\title{
Cosmic ray-induced stratospheric aerosols: A possible connection to polar ozone depletions
}

\author{
E. A. Kasatkina ${ }^{1}$ and O. I. Shumilov ${ }^{1}$ \\ ${ }^{1}$ Institute of North Industrial Ecology Problems, Kola Science Centre RAS, Apatity, Russia \\ Received: 25 May 2004 - Revised: 22 December 2004 - Accepted: 13 January 2005 - Published: 30 March 2005
}

\begin{abstract}
The model calculations of altitude distribution of $\mathrm{CN}$ (condensation nuclei), plausible centers of sulfate aerosol formation after the occurrence of GLE, are presented. Events with relativistic solar protons (i.e. protons with energies $>450 \mathrm{MeV}$ ) are observed at ground level by neutron monitors and called ground-level events (GLEs) (Shea and Smart, 2001). Analysis of experimental data and model calculations permits us to explain some distinctions observed in ozone total content (OTC) variations during several GLEs. For example, model simulations show a significant $\mathrm{CN}$ concentration enhancement during the May 1990 GLEs of relatively "moderate" magnitude, when polar ozone "miniholes" (OTC depletions up to 20\%) have been observed, while no OTC variations and considerable aerosol enhancements were seen during more powerful GLEs (4 August 1972, 2 May 1998, 14 July 2000) (Reagan et al., 1981; Shumilov et al., 1995, 2003). Our results demonstrate that "moderate" GLEs may increase aerosol content significantly and cause ozone "mini-hole" creation.
\end{abstract}

Keywords. Atmospheric composition and structure (aerosols and particles) - Solar physics, astrophysics and astronomy (energetic particles) - Space plasma physics (ionization processes)

\section{Introduction}

Since the discovery of the Antarctic ozone "hole" by Farman et al. (1985) a number of reports concerning ozone research at high latitudes have appeared (Solomon, 1988; Evans, 1990; Larsen and Henriksen, 1990; Taalas and Kyro, 1992). According to these reports no ozone decreases comparable with that in the Antarctic have been observed in the Northern Hemisphere, and only small (up to 30\%) and short-lived (several days) ozone total content depletions or so-called ozone "mini-holes" have been observed in the Arctic (Solomon,

Correspondence to: O. I. Shumilov

(oleg@ aprec.ru)
1988; Evans, 1990; Taalas and Kyro, 1992). The main sources of Arctic ozone "mini-holes", as well as Antarctic ozone "hole" creation, seem to be polar stratospheric clouds (PSC) and sulfate aerosols, and as a consequence the heterogeneous reactions on the surface of aerosol particles (Solomon, 1988; Larsen and Henriksen, 1990). Dynamical processes in the stratosphere have also been considered as another reason for ozone "mini-hole" creation (Taalas and Kyro, 1992). The main sources of sulfate aerosols in the atmosphere are volcanic eruptions, anthropogenic emissions and biological activity. The contribution of each component to aerosol layer formation in the two stratosphere differs in two hemispheres and depends on latitude. Additional aerosols can also be created in the polar atmosphere through the ion nucleation mechanism. The mechanism of the ion nucleation through the ionization process has been developed by Arnold (1982) as a potential source of condensation nuclei $(\mathrm{CN})$ on which stratospheric sulfate aerosols can form (Arnold, 1982; Hofman and Rosen, 1983).

Shumilov et al. $(1995,1996)$ reported that high-energy $(150-300 \mathrm{MeV})$ solar protons can contribute to aerosol layer and initiate ozone "mini-holes" at high latitudes. Taking into account that the low (less than $-78^{\circ}$ ) stratospheric temperatures are rare in occurrence at northern polar latitudes $(10 \%$ days in a year) (Taalas and Kyro, 1992), we consider the solar protons as one of the possible agents influencing the ozone layer and aerosols in Arctic.

In the present paper the results of model calculations of aerosol enhancement after some GLEs in the frame of the ion nucleation mechanism are presented.

\section{Model simulations of stratospheric aerosol increases after occurrence of GLEs}

The main sources of sulfate aerosols in the atmosphere are volcanic eruptions, anthropogenic emissions and phytoplankton activity. Besides these, another factor responsible for aerosol creation in the atmosphere seems to exist. This 


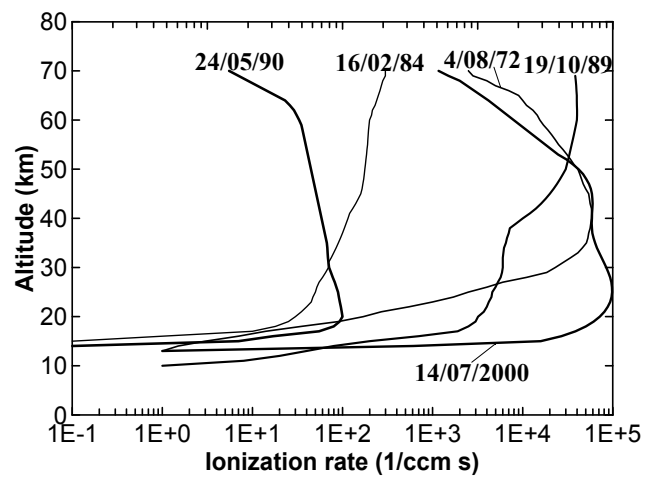

Fig. 1. Ionization rate profiles calculated for GLE events at the time of their maximum.

factor is a ion nucleation process initiated by high-energy solar (SCR) and galactic cosmic rays (GCR) penetrating below the 30-km altitude (Arnold, 1982; Hofman and Rosen, 1983; Yu and Turco, 2000; Yu, 2002). The process implied in the ion nucleation is the growth of ions by association of sulfuric acid molecules to a critical size at which the resulting molecular cluster would be stable against ion-ion recombination.

The rate of ion nucleation is related to the ion production rate (Arnold, 1982; Hofman and Rosen, 1983) and also depends on sulfuric acid vapor concentration $\left[\mathrm{H}_{2} \mathrm{SO}_{4}\right]$, temperature, relative humidity, and air pressure (Yu, 2002). A detailed scheme illustrating the ion-catalyzed nucleation of new ultrafine particles from trace condensable vapors $\left(\mathrm{H}_{2} \mathrm{SO}_{4}\right.$ and $\mathrm{H}_{2} \mathrm{O}$ ) in the atmosphere, which may then grow into new cloud condensation nuclei (CCN), is performed in Carslaw et al. (2002); Yu, (2002). We propose that ion nucleation and aerosol enhancement may play a significant role in ozone "minihole" creation at high latitudes after GLEs (Shumilov et al., 1995, 2003). This result seems to correlate with the detection of large increases of stratospheric aerosols in the Arctic ( $\sim 17 \mathrm{~km}$ altitude) after the occurrence of GLEs (Shumilov et al., 1996).

Figure 1 shows ionization profiles calculated for maximum intensity of some GLEs (4 August 1972, 16 February 1984, 19 October 1989, 24 May 1990 and 14 July 2000). For the ion production rate $\mathrm{Q}\left(\mathrm{cm}^{-3} \mathrm{~s}^{-1}\right)$ calculation the following equation has been used:

$Q(h)=\frac{1}{\varepsilon} \int_{0}^{\infty} \int_{\varphi=0}^{2 \pi} \int_{\theta=0}^{\pi / 2} D(E) E_{i}(E) \sin \theta d \theta d \varphi d E$,

where $E i(E)$ is the energy loss in the i-th altitude slab in $\mathrm{MeV}, \varepsilon=35 \mathrm{eV}$ is the energy for one ion-electron pair production, $D(E)$ is the differential energy spectrum of incident solar protons, $\varphi$ is the azimuthal angle and $\theta$ is the polar angle.

For calculations we used real GOES solar proton data that allowed us to evaluate a real differential spectrum in an energy interval from 1 to $850 \mathrm{MeV}$ (http://spidr.ngdc.noaa.gov/ spidr/). Spectra for 4 August 1972 and 16 February 1984

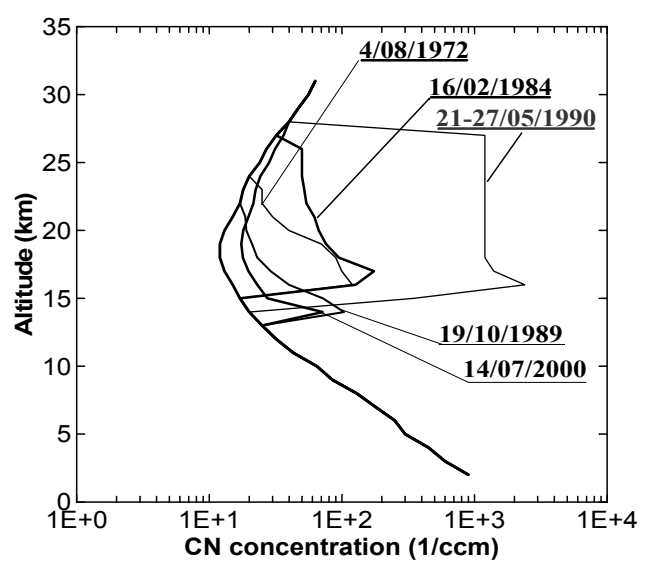

Fig. 2. Model simulations of condensation nuclei $(\mathrm{CN})$ initiated by GLEs.

were estimated using solar proton parameters taken from Reagan et al. (1981) and Hargreaves et al. (1987), respectively.

To calculate aerosol enhancement during GLE events considered we used the ion nucleation theory according to which aerosol particles are formed by ions and $\mathrm{H}_{2} \mathrm{SO}_{4}$ molecules (Arnold, 1982). The ion nucleation rate $\mathrm{J}\left(\mathrm{cm}^{-3} \mathrm{~s}^{-1}\right)$ is related to ion production rate $\mathrm{Q}$ by equation (Hofman and Rosen, 1983):

$J=Q \cdot\left(1+(\alpha Q)^{\frac{1}{2}} / K\left[\mathrm{H}_{2} \mathrm{SO}_{4}\right]\right)^{-N c}$,

where $\alpha$ is the ion recombination coefficient $\left(10^{-7} \mathrm{~cm}^{3} \mathrm{~s}^{-1}\right)$, $\mathrm{K}$ is the association rate coefficient $\left(10^{-9} \mathrm{~cm}^{2} \mathrm{~s}^{-1}\right),\left[\mathrm{H}_{2} \mathrm{SO}_{4}\right]$ is the molecular concentration of sulfuric acid, and $\mathrm{Nc}$ is the number of $\mathrm{H}_{2} \mathrm{SO}_{4}$ in a critically sized embryo. In the stratosphere only $\mathrm{H}_{2} \mathrm{SO}_{4}$ and water molecules can form stable clusters, and $N c$ is equal to $3(\mathrm{~h} \leq 27 \mathrm{~km})$ and $10(\mathrm{~h}>27 \mathrm{~km})$ respectively (Arnold, 1982). Sulfuric acid concentration profiles were taken from Arnold (1982), with a maximum of $10^{5} \mathrm{~cm}^{-3}$ between $\mathrm{h}=15 \mathrm{~km}$ and $\mathrm{h}=27 \mathrm{~km}$. Note that additional sources, such as volcanic eruptions and anthropogenic emissions, can increase the $\left[\mathrm{H}_{2} \mathrm{SO}_{4}\right]$ level at high latitudes by two orders (Hofman and Rosen, 1983; Langner et al., 1992). The eruption of El Chichon on 14 April 1984, for example, has created a high level of sulfuric acid supersaturation $\left(>10^{7}\right.$ molecules $\mathrm{cm}^{-3}$ ) (Hofman and Rosen, 1983). Typical sulfuric acid vapor concentrations according to some measurements and estimates lie in the range of perhaps $10^{6}-10^{7} \mathrm{~cm}^{-3}$ (Eisele and Tanner, 1993; Weber et al., 1996).

We assumed that nucleation event durations roughly coincide to solar proton event periods ( $113 \mathrm{~h}$ for May 1990 GLEs, $4 \mathrm{~h}$ for 16 February 1984 GLE and 4 August 1972 GLE, $10 \mathrm{~h}$ for 19 October 1989 GLE; 14 July 2000 GLE). Of course, we have to take into account condensation and coagulation processes. But it's only a simple model simulation (most likely some physical estimates). There are also other nucleation processes in the troposphere and stratosphere, such as binary 
homogeneous nucleation of sulfuric acid $\left(\mathrm{H}_{2} \mathrm{SO}_{4}\right)$ and water vapor $\left(\mathrm{H}_{2} \mathrm{O}\right)$ and heteromolecular condensation of $\left(\mathrm{H}_{2} \mathrm{SO}_{4}\right)$ on the particles. These processes, as well as some other ones, including coagulation and sedimentation, are taken into account in more complicated models (Timmreck and Graf, 2000), and their application is beyond the scope of the paper.

Figure 2 demonstrates condensation nuclei $(\mathrm{CN})$ profiles calculated using Eq. (2) for GLEs shown in Fig. 1.

\section{Discussion and conclusions}

As illustrated in Fig. 1, the vertical profiles shown have considerable discrepancies above $20 \mathrm{~km}$ : ionization rates on 14 July 2000, 4 August 1972 and 19 October 1989 exceed other two by two orders of magnitude. These discrepancies are connected to higher proton fluxes during 4 August 1972, 19 October 1989 and 14 July 2000 GLE events. We also may add that no OTC depletions have been observed after these events (Shumilov et al., 2003). On the other hand, the two largest GLEs (19 October 1989 and 14 July 2000) caused significant NOx productions and ozone decreases at stratospheric altitudes on the data of rocket UARS spacecraft measurements, and also according to the modelling based on the ordinary gas-phase photochemistry (Zadorozhny et al., 1992; Jackman et al., 2001; Krivolutsky, 2001, 2003; Shumilov et al., 2003).

Previously it was shown (Shumilov et al., 1995) that OTC depletions observed during 29 September 1989 and May 1990 GLEs could not be explained using only the homogeneous photochemical model introduced by Crutzen et al. (1975). Our calculations of OTC depletions based on additional HOx and NOx production during solar proton events (Crutzen et al., 1975; Jackman et al., 1980) were one order of magnitude less than the observed ones (Shumilov et al., 1995). This fact by no means implies that gas-phase photochemical theory only cannot be used to interpret ozone "mini-hole" creation during GLEs. For example, homogeneous theory describes very well the NOx variations and ozone depletions caused by solar protons above the $40-\mathrm{km}$ altitude, where model calculations and experimental results coincide (Jackman et al., 1980, 2001; Zadorozhny et al., 1992; Krivolutsky, 2001, 2003; Shumilov et al., 1995, 2003). As it is evidenced from Fig. 1, the 24 May 1990 GLE event was not a powerful one, however, during this event, ozone "miniholes" have been observed (Shumilov et al., 1995).

In our work we consider the ion nucleation mechanism (Arnold, 1982; Hofman and Rosen, 1983) as one of the possible sources of enhanced concentration of ultrafine particles or condensation nuclei $(\mathrm{CN})$ in the high-latitude atmosphere after some proton events of GLE type. Such ultrafine particles can grow by condensation to the size of typical cloud condensation nuclei $(\mathrm{CCN}) \sim 30-80 \mathrm{~nm}$ within 1 day (Kulmala et al., 1998; Birmili and Wiedensohler, 2000). We suppose this mechanism to be responsible for ozone "minihole" creation after GLEs. It should be noted that according to another hypothesis ("electrofreezing" mechanism), the variations in cosmic rays change the charge status of aerosols that affect the ice production rate and cloud microphysics (Tinsley and Dean, 1991; Tinsley, 2000). On the surface of these particles a complex set of heterogeneous processes takes place which lead to significant ozone depletions (Prather, 1992).

Figure 2 gives a possible explanation why ozone "miniholes" have been observed only after May 1990 GLEs in spite of the fact that these events were the "moderate" ones (see Fig. 1). Note that there were 3 GLEs from 21 to 27 May, 1990 (21, 24, 26 May) that, as would be expected have an accumulated effect on the ozone depletion observed. Large proton fluxes during powerful GLE events (4 August 1972, 19 October 1989 and 14 July 2000) have effectively reduced the nucleation rate, because for large $\mathrm{Q}$ (more than $100 \mathrm{~cm}^{-3} \mathrm{~s}^{-1}$ ) the ion recombination rate predominates. Limiting $Q$ values when further increase of $Q$ leads to a $\mathbf{J}$ decrease are $\sim 100 \mathrm{~cm}^{-3} \mathrm{~s}^{-1}$ and $1000 \mathrm{~cm}^{-3} \mathrm{~s}^{-1}$ for $\left[\mathrm{H}_{2} \mathrm{SO}_{4}\right]$ values equal to $3 \times 10^{6} \mathrm{~cm}^{-3}$ and $10^{7} \mathrm{~cm}^{-3}$, correspondingly (Hofman and Rosen, 1983). We would thus expect $\mathbf{J}$ to increase nearly linearly with $\mathrm{Q}$ only for moderate solar proton events (see Fig. 2 from Hofman and Rosen, 1983). The largest GLEs (4 August 1972, 19 October 1989, and 14 July 2000) could effectively reduce the nucleation rate.

We can compare these calculations with experimental results only for one (16 February 1984) GLE event, when a stratospheric aerosol enhancement has been observed at auroral latitudes (Shumilov et al., 1996; Kasatkina et al., 1999). Recent aircraft measurements have demonstrated evidence for cosmic ray-induced aerosol formation in the upper troposphere (Eichkorn et al., 2002). Furthermore, ions induced by solar protons can account for observation of unusual midstratospheric aerosol layers in the high-latitude stratosphere (Gerding et al., 2003), although the authors don't share this point of view. In a series of recent papers it was noted as well that air ions produced by galactic cosmic rays may play an important role in the production of new aerosol particles that may affect the cloud properties (Yu and Turco, 2000, 2001; Yu, 2002; Carslaw et al., 2002; Marsden and Lingenfelter, 2003). These model simulations seemed to support experimental data indicating the presence of a significant positive correlation between GCR intensity and the frequency of low clouds, below $\sim 3.2 \mathrm{~km}$ (Marsh and Svensmark, 2000; Palle and Butler, 2000).

It is seen from Fig. 2 that $\mathrm{CN}$ concentration for May 1990 GLEs exceeds by about two orders the background level. According to Prather (1992), such a large additional CN amount can lead to catastrophic ozone total content depletions (more than $10 \%$ per day).

The results of model simulations based on the ion nucleation mechanism have shown that moderate GLEs may contribute to aerosol content significantly and initiate ozone "mini-hole" creation. The goal of our simulations was to demonstrate that the solar protons may cause, under specific combinations of some atmospheric parameters $\left(\left[\mathrm{H}_{2} \mathrm{SO}_{4}\right]\right.$, temperature, relative humidity, pressure, and as well solar proton spectral features), considerable (up to 25\%) ozone total content depletions. Therefore, the simple (linear) 
correlation between solar proton flux and the values of ozone total content depletions is hardly consistent from the physical point of view.

Acknowledgements. This research was supported by the Russian Foundation for Basic Research (grant N 05-06-97528) and by the Regional Scientific Program of Murmansk region.

Topical Editor U.-P. Hoppe thanks a referee for his/her help in evaluating this paper.

\section{References}

Arnold A.: Ion nucleation - a potential source for stratospheric aerosols, Nature, 299, 134-137, 1982.

Birmili, W. and Wiedensohler, A.: New particle formation in the continental boundary layer: Meteorological and gas phase parameter influence, Geophys. Res. Lett., 27, 3325-3328, 2000.

Carslaw, K. S., Harrison, R. G., and Kirkby, J.: Cosmic rays, clouds, and climate, Science, 298, 1732-1737, 2002.

Clarke, A. D., Kapustin, V. N., Eisele, F. L., Weber R. J., and McMurry, P. H.: Particle production near marine clouds: Sulfuric acid and predictions from classical binary nucleation, Geophys. Res. Lett., 26, 2425-2428, 1999.

Crutzen, P., Isaksen, I., and Reid, G.: Solar proton events: Stratospheric sources of nitric oxide, Science, 189, 457-458, 1975.

Eichkorn, S., Wilhelm, S., Aufmhoff, H., Wohlfrom, K.-H., and Arnold, F.: Geophys. Res. Lett., 29, 43-46, 2002.

Eisele, F. L. and Tanner, D. J.: Measurement of the gas phase concentration of $\mathrm{H}_{2} \mathrm{SO} 4$ and methane sulfonic acid and estimates of $\mathrm{H}_{2} \mathrm{SO} 4$ production and loss in the atmosphere, J. Geophys. Res., 98, 9001-9010, 1993.

Evans, W. F. J.: Ozone depletion in the Arctic vortex at Alert during February 1989, Geophys. Res. Lett., 17, 167-170, 1990.

Farman, J. C., Gardiner, B. G., and Shanklin, J. D.: Large losses of total ozone in Antarctica reveal seasonal $\mathrm{ClOx} / \mathrm{NOx}$ interaction, Nature, 315, 207-210, 1985.

Gerding, M., Baumgarten, G., Blum, U., Thayer, J. P., Fricke, K.H., Neuber, R., and Fiedler, J.: Observation of an unusual midstratospheric aerosol layer in the Arctic: possible sources and implications for polar vortex dynamics, Ann. Geophys., 21, 10571069, 2003,

SRef-ID: 1432-0576/ag/2003-21-1057.

Hargreaves, J. K., Ranta, H., Ranta, A., Turunen, E., and Turunen, T.: Observations of the polar cap absorption event of February 1984 by the EISCAT incoherent scatter radar, Planet. Space Sci., 35, 947-958, 1987.

Hofman, D. J. and Rosen, J. M.: Condensation nuclei events at $30 \mathrm{~km}$ and possible influences of solar cosmic rays, Nature, 302, 511-514, 1983.

Jackman, C. H., Frederick, J. E., and Stolarski, R. S.: Production of odd nitrogen in the stratosphere and mesosphere: An intercomparison of source strengths, J. Geophys. Res., 85, 7495-7505, 1980.

Jackman, C. H., MacPeters, R. D., Labow, D. J., Fleming, E. L., Praderas, C. J., and Russel, J. M.: Northern Hemisphere atmospheric effects due to the July 2000 solar proton event, Geophys. Res. Lett., 28, 2883-2886, 2001.

Kasatkina, E. A., Shumilov, O. I., and Vashenyuk, E. V.: Corpuscular solar activity as a source of aerosols in the stratosphere, Kosmicheskie issledovania, 37, 163-167, 1999 (in Russian with English translation).
Krivolutsky, A. A.: Cosmic ray influence on chemical composition of the atmosphere of the Earth, Adv. Space Res., 27, 1993-2002, 2001.

Krivolutsky, A. A.: History of cosmic ray influence on ozone layer - key steps, Adv. Space Res., 31, 2127-2138, 2003.

Kulmala, M., Toivonen, A., Makela, J. M., and Laaksonen, A.: Analysis of the growth of nucleation mode particles observed in Boreal forest, Tellus, 50, 449-462, 1998.

Langner, J., Rodhe, H., Crutzen, P. J., and Zimmermann, P.: Anthropogenic influence on the distribution of tropospheric sulphate aerosol, Nature, 359, 712-716, 1992.

Larsen, S. H. H. and Henriksen, T.: Persistent Arctic ozone layer, Nature, 343, 124-126, 1990.

Marsden, D. and Lingenfelter, R. E.: Solar activity and cloud opacity variations: A modulated cosmic ray ionization model, J. Atmos. Sci., 60, 626-636, 2003.

Marsh, N. and Svensmark, H.: Low cloud properties influenced by cosmic rays, Phys. Rev. Lett., 85, 5004-5007, 2000.

Novakov, T. and Perner, J. E.: Large contribution of organic aerosols to cloud condensation nuclei concentration, Nature, 365, 823-826, 1993.

Palle, E. and Butler, C. J.: The influence of cosmic rays on terrestrial clouds and global warming, Astron. Geophys., 41, 18-22, 2000.

Prather, M.: Catastrophic loss of stratospheric ozone in dense volcanic clouds, J. Geophys. Res., 97, 10 187-10 191, 1992.

Reagan, J. B., Meyerott, R. E., Nightingale, R. W., et al.: Effects of the August 1972 solar particle events on stratospheric ozone, J. Geophys. Res., 86, 1473-1494, 1981.

Shea, M. A. and Smart, D. F.: Solar proton and GLE event frequency: 1955-2000, Proc. 27th International Cosmic Ray Conference, 3401-3404, 2001.

Shumilov, O. I., Kasatkina, E. A., Henriksen, K., and Raspopov, O. M.: Ozone "miniholes" initiated by energetic solar protons, J. Atm. Terr. Phys., 57, 665-671, 1995.

Shumilov, O. I., Kasatkina, E. A., Henriksen, K., and Vashenyuk, E. V.: Enhancement of stratospheric aerosols after solar proton event, Ann. Geophys., 14, 1119-1123, 1996,

SRef-ID: 1432-0576/ag/1996-14-1119.

Shumilov, O. I. and Kasatkina, E. A.: Solar cosmic ray effects in atmospheric chemistry evidenced from ground-based measurements, Adv. Space Res., 31, 2157-2162, 2003.

Solomon, S.: Overview of the polar ozone issue, Geophys. Res. Lett., 15, 845-846, 1988.

Taalas, P. and Kyro, E.: 1987-1989 total ozone and ozone sounding observations in Northern Scandinavia and Antarctica, and the climatology of the lower stratosphere during 1965-1988 in Northern Finland, J. Atmos. Terr. Phys., 54, 1089-1099, 1992.

Timmreck, C. and Graf, H-F.: A microphysical model for simulation of stratospheric aerosol in a climate model, Meteorologische Zeitschrift, 9, 263-282, 2000.

Tinsley, B. A. and Dean, G. W.: Apparent tropospheric response to $\mathrm{MeV}-\mathrm{GeV}$ particle flux variations: a connection via electrofreezing of supercooled water in high-level clouds? J. Geophys. Res., 96, 22 283-22 296, 1991.

Tinsley, B. A.: Influence of solar wind on the global electric circuit, and inferred effects on cloud microphysics, temperature, and dynamics in the troposphere, Space Sci. Rev., 94, 231-258, 2000.

Tolbert, M. A., Rossi, M. J., and Golden, D. M.: Heterogeneous interactions of chlorine nitrate, hydrogen chloride, and nitric acid with sulphuric acid surfaces at stratospheric temperatures, Geophys. Res. Lett., 15, 847-850, 1988. 
Tolbert, M. A.: Sulfate aerosols and polar stratospheric cloud formation, Science, 264, 527-528, 1994.

Weber, R. J., Marti, J. J., McMurray, P. H., Eisele, F. L., Tanner, D. J., and Jefferson, A.: Measured atmospheric new particle formation rates: Implications for nucleation mechanisms, Chem. Eng. Comm., 151, 53-62, 1996.

Yu, F. and Turco, R. P.: Ultrafine aerosol formation via ionmediated nucleation, Geophys. Res. Lett., 27, 883-886, 2000.
Yu, F. and Turco, R. P.: From molecular clusters to nanoparticles: The role of ambient ionization in tropospheric aerosol formation, J. Geophys. Res., 106, 4797-4814, 2001.

Yu, F.: Altitude variations of cosmic ray induced production of aerosols: Implications for global cloudiness and climate, J. Geophys. Res., 107, 1029-1038, 2002.

Zadorozhny, A. N., Kihtenko, V. N., Kokin, G. A., et al.: The reaction of the middle atmosphere to the solar proton events in October 1989, Geomagn. Aeron., (in Russian with English translation), 32, 184-191, 1992. 